\title{
Organization and Flexibility: How to Build a Resilient Organization in the Context of Industry 4.0?
}

\author{
Emil Wojčák ${ }^{1}$, Michaela Poláková ${ }^{1}$, Lukáš Copušs ${ }^{1}$, Juliet Horváthová Suleimanová ${ }^{1}$ \\ ${ }^{1}$ Comenius University in Bratislava, Faculty of Management, Slovakia \\ lukas@copus.sk
}

\begin{abstract}
The increasing importance of flexibility for the competitiveness of organizations in the digital age where changes are driven significantly by the fourth industrial revolution is the main issue discussed in the article. The aim is to identify the main pillars on which managers should focus when creating a resilient organization and to point out the forms of flexible work arrangements that could be applied. The need for flexibility which underlies viability and resilience of organization results from the action of two forces: the extropy representing intelligence, flexibility and creativity of the organization and the entropy representing the tendency of the system to move to a disordered state. Organizational changes are metaphorically represented as thermodynamic changes in four basic stages. The result of theoretical research is a new model of flexible organization introduced in the article with an emphasis on flexible work arrangements as these may help increase flexibility in various forms including numerical, functional, localization and time flexibility. Even though the fourth industrial revolution is built on pillars of digitalization and application of technologies, their effective use is not possible without people. They are the driving force of the transformation of the organization within the concept of Industry 4.0. Our model of organization built on flexibility represents the possibility to cope with changes through effective use of human potential supported by flexible work arrangements.
\end{abstract}

Keywords: resilient organization, flexible forms of work arrangements, functional flexibility, localization flexibility, numerical flexibility, time flexibility, industry 4.0 .

\section{Introduction}

The intensity, quantity and speed of changes are significantly influenced by technological progress and the associated rapid information and knowledge acquisition, knowledge-intensive activities, self-organizing, increased connectivity and interaction in the virtual world, effacing geographical and cultural boundaries resulting from globalization. Digitalization and the use of the Internet are perceived as key factors leading to the Fourth Industrial Revolution and the emergence of digital, smart and innovative businesses, the exact form and operation of which is difficult to determine. The digital age, which brings a lot of change and uncertainty, thus creates an envi- 
ronment with a high degree of entropy. The answer to a high level of entropy in the environment may be an increase in extropy, which represents the level of intelligence of the system, its awareness, viability and ability to grow. For organizations, this means the possibility of sustainable success thanks to their ability to adapt to current requirements, modify the organizational structure and apply a higher level of education. We consider flexibility to be one of the key factors for such conduct in an organization.

The aim of the article is to identify the main pillars on which the manager should focus when creating a resilient organization and to point out the forms of flexible work arrangements that could be applied. The model of the flexible organization presented in this article emphasizes the ability of the organization to respond to changes and uncertainty of the environment with an increased level of intelligence, where the decisive element using information and knowledge is not technology, system or artificial intelligence, but people. Technology, information and knowledge are considered tools the use of which depends on the ability, willingness and motivation of people who use them in accordance with the ever-changing needs of people, organizations or markets. If managers want to shape a future that works for all they are called for putting people first, empowering them and constantly reminding ourselves that all of these new technologies are first and foremost tools made by people for people [1]. For an organization as a "living organism" made up of people, it will be important to build flexibility in various forms including numerical, functional, localization and time flexibility.

\section{Theoretical framework}

The challenges we face today and those we will confront in the future require new ways to consider and understand the complex, interconnected and constantly changing world in which we live and work. We see further discussed ideas as useful for pointing out the importance of flexibility and viability of organization as these properties may contribute to the resilience of organization, so important in a highly complex and turbulent environment.

Increased uncertainty of environment influences organizational structure and processes as it forces organizations to find a new way to cope with continuous change in order to survive. Uncertainty can attract a living system to higher complexity, so that the system absorbs uncertainty from its environment and transforms it to an organization, thus increasing its internal complexity. It follows that the living system evolves because of its environment's entropy [2]. Entropy as a property of a system identifies its tendency to move toward a completely random or disordered state. In a closed system heat (defined as "the transfer of energy due to a temperature gradient" [3], energy transfer between environment and system) [4] added to the system is given, the entropy of the system changes due to the addition of heat [5]. So, according to the Second Law of Thermodynamics entropy in closed system is constantly increasing. However, in real processes, within open systems, the change in entropy of the system is greater than the heat added. These processes can continue in the preferred direction spontaneously without the input of energy from the surroundings [2]. Such a system 
supports self-organization and it is not influenced causally from outside but adjusts its internal processes in case of changes in the environment.

A system facing uncertainty uses flexibility as an adaptive response to cope with change. The flexibility in the action of the system depends on the decision options or the choices available and on the freedom with which various choices can be made [6]. Self-organization can only occur in open systems having an innate capacity to import energy which suggests that the more turbulent the environment for an organization, the more energy must be imported to sustain the self-organization. In the context of an organization, energy is likely to mean new ways of doing business [7], performing the tasks, communication, new employees etc. Organizational energy to learn and selfdevelop [8] leads as to the concept of extropy. Extropy represents the extent to which a social system possesses intelligence, functional order, vitality, life, experience, and capacity to drive improvement and growth [9]. Extropy is the tendency of autonomous systems to create order from chaos, which is contrary to the creation of entropy and consistent with the notions of emergence and self-organization [10].

The increase in change and the growing uncertainty in the business environment can be compared to the heating or overheating of the environment, which naturally "warms" organizations. What enables the organization to cope with the growing degree of entropy is the degree of intelligence of the system. And we will perceive the level of intelligence of the system through the intelligence of human resources - employees as bearers of knowledge, which set in motion other resources of the organization.

By transferring the knowledge of thermodynamics to the field of management, we have described four basic stages of development of organizations depending on the entropy of the environment represented by different approaches in management. Figure 1 depicts how changes "heat" the environment and make an organization react for the sake of survival. Organizational changes are metaphorically represented as thermodynamic changes in four basic stages - Ice cube, Melting ice cube, Water and Vapour. These are also put in historical context. By understanding entropy as a measure of disorder, if matter and energy are distributed in a disordered way, as in a gas, then the entropy is high; if energy and matter are stored in an ordered manner, as in a crystal, then the entropy is low [11]. An increasing entropy of the environment boosts the necessity of extropy in the organization system - that is - the ability to be intelligent, flexible and creative enough to adapt and survive.

Ice Cube as the first stage of development is characterized by a solid structure. In terms of thermodynamics, the ice cube keeps its shape. The ice cube represents an organization with a solid hierarchical structure, a high degree of formalization and firm control. The defined procedures had to be followed and the manager, was there to point and control above all. In terms of the development of management ideas, we could assign this stage to the historically first approach to scientific management. Organization was perceived as a closed system behaving according to mechanical principles. The low degree of uncertainty of the environment did not require a higher degree of extropy in terms of higher system intelligence, creativity, or the creation of unique solutions and self-management. 


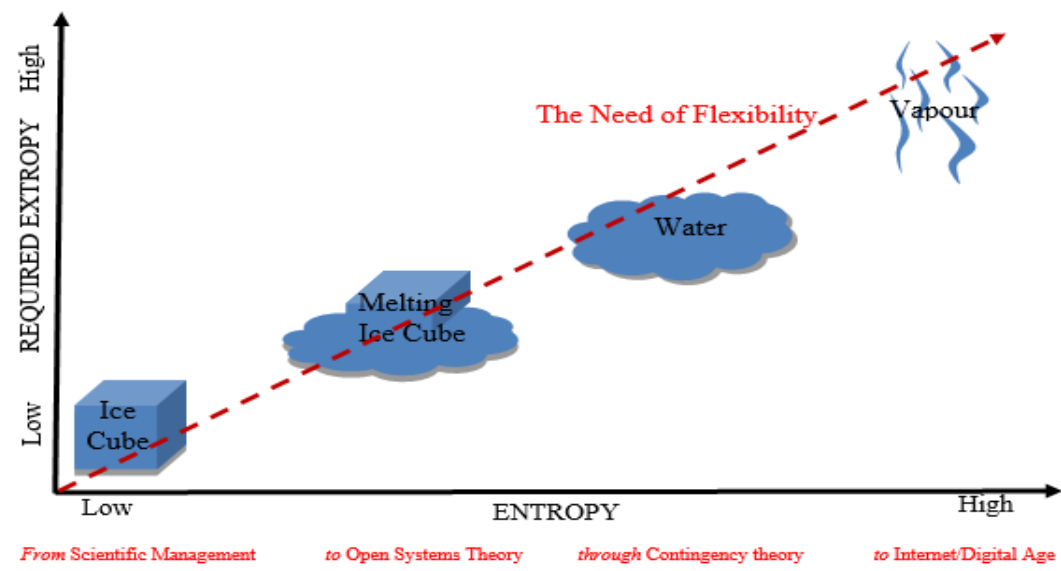

Fig. 1. Increase in Entropy in Environment and Organizations (Source: Developed by authors)

Melting Ice Cube represents the second stage of development when the Ice Cube enters a warmer environment and melts. In this case, the organization faces a degree of uncertainty. Like in the case of a real melting ice cube, when a certain part no longer has a solid molecular structure, a part is created in the organization where activities are growing that are no longer defined by precise rules with the need to be strictly followed and controlled. There is room for the independent creative activity of employees. Therefore, a higher rate of extropy is needed to make the organization resilient and efficient which creates a need for a higher level of skills, knowledge and commitment of employees to handle some activities without a precise workflow.

Regarding the history of management thoughts, recognized value of human beings in an organization corresponds with behavioral approach. There is also shift from understanding the organization as a closed system to understanding it as an open system. Bertalanffy [12] was developing the concept of open systems and focused on the interaction of the entity with its environment which consequently led to the second assumption of the system being dynamic and changing constantly.

Water is characterized by a high degree of entropy. Ice cube melts and water remains melted, which is held together only by the surface tension of the water. If the previous stages showed the organization behaves not always rationally and changes constantly, then in this stage that might be represented by contingency theory. This approach argued that an organization evolves and changes in different ways, therefore should be managed in different ways depending on its specific situation. According to Kaufman [13], there are many pathways to development, biological and intellectual; there is no "the one and only way". Certainly, for an order which arises spontaneously from interactions, there is no pre-set way. Whatever 'method' our universe is using for its ordering, it must have flexibility.

Ideas of Woodward [14], Burns and Stalker [15, 16] offered alternative ways of understanding how an organization works again based on ideas of biology. Organic or "organismic" organization point out the idea of an organic organization with less rigid structures and more integration between parts of the organization. In relation to this, 
the authors like Dixon [17], Argyris and Schön [18], Senge [19] emphasized the importance of flexibility and learning in order to make organization dynamic, contextsensitive while capable of maintaining coherence. The managerial task is not to control, regulate or validate this process, but to keep it coherent by using facilitation [20]. The manager is expected to be able to lead and support employees, to create conditions so that they are able to look for the best possible solutions together.

Vapour is characterized by the infinity of the system. Steam represents many ties with the environment, which quickly arise, disappear and the new ones re-emerge and interact with each other. The condition for the successful functioning of the organization is a significant number of knowledge workers who are independent.

This requires a shift in understanding the organization rather as a complex adaptive system, or as an intelligent complex adaptive system. Complex systems are not readily predictable, because even minute variations in starting conditions can cause large, nonlinear, variations in outcomes [21]. Bennet et al. [22] suggest for future organizations a concept of an intelligent complex adaptive system (ICAS) - a living organization that will be composed of living sub-systems that combine and interact to provide the capabilities of an advanced, intelligent, techno-sociological adaptive enterprise. These organizations are frequently composed of hierarchical levels of self-organizing workers. By providing workers with the freedom to think and act on their own, the organization will possess certain overall properties essential for survival and growth in the anticipated environment. The resulting intelligence provides advantages that include innovation, learning, adaptation and quick response to new and trying situations. And if organizations are like complex adaptive systems, then managers are agents in those systems and are themselves such systems interacting at their own local level. The dynamics and the emergent behavior arise through their participation not their acts of design [6].

From Industry 4.0 perspective the evolution of business activity has been going from companies and markets to digital networks [23] and when an organization uses more technologies instead of visible work areas, the traditional business activity should be replaced by a concept of organization as a flexible function. Demands for greater flexibility may afford opportunities for employers to have more freedom and control over their working arrangements. Flexible work arrangements that build on the capacity of employees for self-organization and self-leadership are an increasing phenomenon in the world of work [24].

\section{$3 \quad$ Resilient Organization Built on Flexibility}

Nowadays, work thanks to ICT can be executed at the client's place, at home, in a means of transport or, for instance, in a café and at required times. Such an arrangement influences production methods, procedures as well as the work arrangements themselves. Eurofound defines these forms from the perspective of employment as "employment relationships not conforming to the standard or 'typical' model employment" [25]. Organizations thus must cope with different working time structures (Time flexibility), place of work (Localization flexibility), increasing functional skills requirements (Functional flexibility) and changing number of employees as needed 
(Numerical flexibility). Functional and Numerical flexibility have already been addressed by Atkinson in the model of the flexible organization [26]. We have extended the model (Figure 2) with Time and Localization flexibility and linked it to financial aspects as well. These types of flexibility are closely related to the use of Flexible forms of work arrangements addressed by many research institutions (e.g. Eurofound; International Labor Organization; and many authors, e.g. Pollert [27], Zeytinoglu [28], Leonard [29], Bredgaard [30]). Findings from the research show the positive impact of flexible arrangements on engagement of employees, improved performance, employee mental health and well-being [31, 32]. Companies benefit from improvement in work-life balance, which can lead to increased motivation and reduce turnover, and from reduction in the need for office space and associated costs [33].

Our model suggests the areas the resilient organization/organization built on flexibility should focus on: especially Functional Flexibility, Numerical Flexibility, Localization Flexibility and Time Flexibility. These four areas are tied to the financial resources of the organization.

Localization flexibility is largely enabled by Telework. This is work performed either at home or in another place, which is far from the headquarters of the employer's office or operation. Employee works remotely from different places: satellite centers, street work and work from home $[35,36]$. Telework as a typical example of localization flexibility is also related to time flexibility. This flexibility, combined with time, appears in many professions where information and communication technologies and the Internet are used to perform work [34]. Financial aspect: to reduce operation costs (air conditioning, maintenance of buildings, equipment, parking spaces, etc.).

Functional flexibility refers to employees who perform the tasks necessary for the success of the organization. They have a wider range of skills. They often do not perform work precisely defined by job description or job position but perform a wide range of duties. In addition, their work is not limited to activities of a certain hierarchical level. They often become the most important employees of the organization, they learn naturally, they acquire new skills.

Financial aspect: employees who perform various tasks have a wide range of skills, should be remunerated above the normal wage for their contribution and potential. Such people can make decisions faster, they see work in a broader context, so they can avoid unnecessary mistakes and a waste of time and finances.

Relation A refers to the relationship between Localization and Functional flexibility. There is no doubt that a suitable candidate for Localization flexibility (for example, working two days a week from home) should have Functional flexibility, should be responsible, have more skills to be able to solve problems independently.

Time flexibility means an opportunity for organizations to flexibly cover planned or unexpected increases or decreases in working hours. The goal is to be available when needed. Thus, the organization must flexibly adapt working hours to the immediate need, be available to its clients to a greater extent, and thus increase its competitive capabilities. Time flexibility is also required within internal processes, for example, teleconferencing in multinational organizations with branches in states in different time zones. Alternatively, changes are made, where the beginning and end of 
working hours are adjusted continuously. Forms of work organization are used here, such as Flexible-time, Time banking schemes, Compressed working hours, etc. [34].

From a financial point of view: these forms will significantly save the costs associated with wage compensation in traditional overtime.

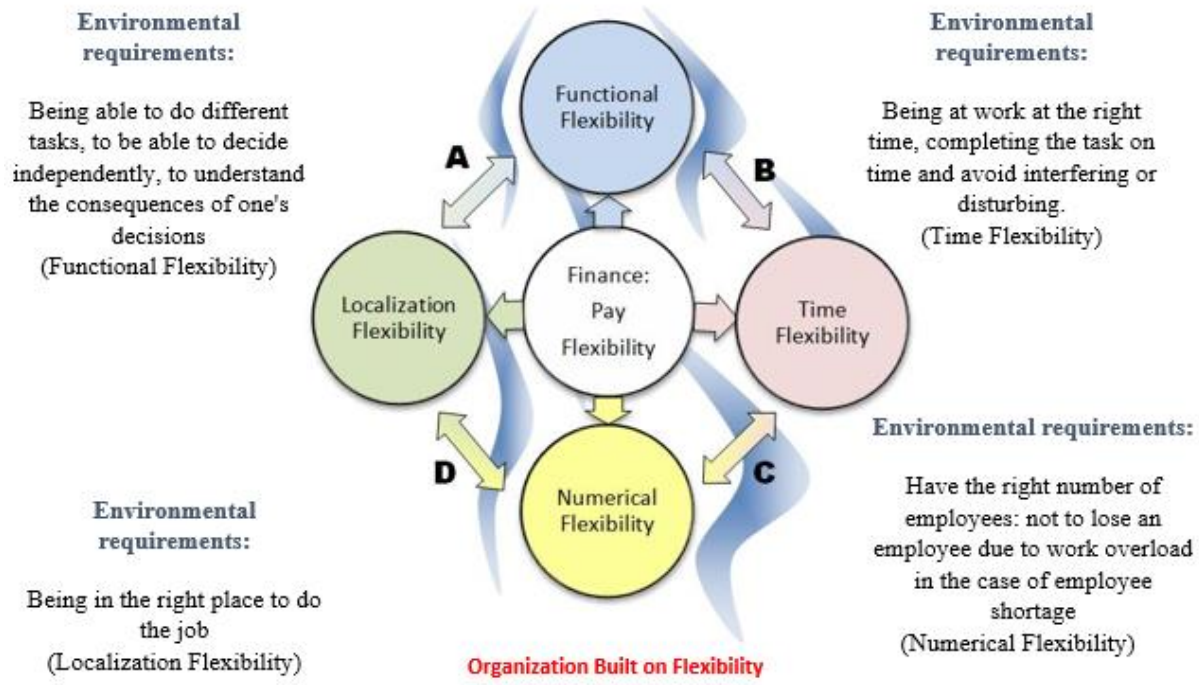

Fig. 2. Model of Organization Built on Flexibility (Source: Developed by authors)

Relation B between Time flexibility and Functional flexibility. If Time flexibility is implemented as a benefit and the employees understand that they have room for further improvement of their skills, they may become functionally flexible.

Numerical flexibility indicates the ability of the organization to adjust the number of employees or the number of hours worked to meet the needs of the organization. An increase in demand for products leads to an increase in the number of employees, and conversely, when it decreases, the number of working hours change or is reduced. The organization should have plans with the right forecasts to predict the fluctuating need for more or fewer employees and respond flexibly to these requirements. Nowadays, a significant number of employees work in the form of a fixed-term contract, or in part-time, or as self-employed. Financial aspect: income from leasing employees, when self-employed it is possible to save, they are not registered as employees of the organization (they use their own resources to perform work, they do not have levies as employees).

Relation C represents the possibility of mutual interaction of both Numerical and Time flexibility. That is, how to deal with a more demanding time range without hiring additional employees, for example by extending the employee's working time beyond the required 8 hours per day (if the employee sees this as an opportunity in terms of financial benefit) or by changing the working hours through setting different start and end times (so that we do not waste human resources and their presence in the workplace is ensured by a sufficient number when needed). 
Relation D between Numerical and Localization flexibility suggests how to deal with a change in the number of employees, whether increasing or decreasing, and working outside the organization. Here, agency employees or the self-employed come to the fore. They fulfill both types of flexibility.

Pay Flexibility affects the possibilities of introducing different types of flexibility. Pay flexibility represents the ability of the wage system to respond to changes in demand for workers and labor market supply. At the same time, it represents the ability to reward and encourage good performance, talent or potential. This element of flexibility is important for employers as a means of directly linking costs to the organization's outputs. In addition, it affects the prospect of other types of flexibility.

Industry 4.0 has a significant impact on the way the company is organized. The knowledge and skills of employees play a key role in fulfilling everyday responsibilities including the introduction of flexible forms of work organization, the use of which is conditioned by the introduction and use of modern technologies to ensure communication in the forms of mobile communication, such as cell phones, laptops, online communication platforms and access to teleconference resources [37]. According to the 2016 Global Survey: PWC's Industry 4.0 [38], the biggest challenges for businesses are the lack of digital culture, appropriate training and the lack of digital skills of employees.

\section{Conclusions}

If an organization is to secure a long-term existence on today's market, employees must change their understanding of work. They are expected to change their behavior and attitudes towards work mainly in terms of answering the questions: Where will I work? When will I work? and How long will I work for them? What skills do I need? Technological development is the motor of change and in this context telework resonates the most among flexible work arrangements. Teleworking develops also with technological advances and shifts from "office from anywhere at any time" to the "virtual office" (Eurofound and ILO [33]). Furthermore, teleworking receives much attention, prior to the COVID-19 pandemic. With the COVID-19 pandemic, the percentage of workers teleworking has risen tremendously, as companies have taken steps to help the practice in an effort to keep their operations ongoing [39].

In general, flexible work arrangements offer a fairly wide range of alternatives to design a Resilient Organization. It is influenced by situational factors, differences in organizations, the manager must be a researcher who selects and applies procedures to achieve the goal.

The aim of the article was to identify the main pillars on which the manager should focus when creating a resilient organization and to point out the forms of work arrangements that s/he can apply, these being Flexible forms of work arrangements. If an organization wants to be able to withstand constant change and seize opportunities and eliminate the impact of threats, it must be flexible, namely functionally flexible, time-flexible, location-based and numerically flexible. We perceive the importance of these types of flexibility as particularly important in the context of Industry 4.0. We are convinced that the four types of flexibility (Functional flexibility, Time flexibility, Localization flexibility and Numerical flexibility) which are acquired through Flexible 
forms of work arrangements, help an organization to become highly responsive on today's market. Even the current global pandemic convinces us that flexible forms of work organization will gradually become a necessity and the call for their use will be getting louder in the future. Fourth industrial revolution requires of the future smart organizations the ability to handle complexity with flexibility.

\section{Acknowledgements}

This research was supported and funded by APVV-17-0656 titled Transformation of Paradigm in Management of Organizations in the Context of Industry 4.0.

\section{References}

1. Schwab, K.: The Fourth Industrial Revolution. New York, Crown Business (2017).

2. Mavrofides, T. et al.: On the Entropy of Social Systems: A Revision of the Concepts of Entropy and Energy in the Social Context. Syst. Res. (28), 353-368 (2011).

3. Nellis, G., Klein, S.: Heat Transfer. Cambridge, Cambridge University Press (2009).

4. Hens, H. S. L.: Building Physics -- Heat, Air and Moisture: Fundamentals and Engineering Methods with Examples and Exercises. New Jersey, John Wiley \& Sons (2012).

5. Reibe, D.: Fundamentals of Environmental Engineering. Cleveland, CRC Press (2017).

6. Stacey, R. D., Griffin, D., Shaw, P.: Complexity and Management. Fad or radical challenge to systems thinking? London: Routledge (2000).

7. Grobman, G. M.: Complexity theory: a new way to look at organizational change. Public Administration Quarterly 29(3) (2005).

8. Shermon, G.: Digital Talent - Business Models and Competencies. Morrisville: Lulu Press (2017).

9. Bailey, K. D.: Social entropy theory. New York, State University of New York Press (1990).

10. Yoljes, M.: Organizations as complex systems: an introduction to knowledge cybernetics. Charlotte, IAP - Information Age Pub Inc. (2016).

11. Atkins, P. The Laws of Thermodynamics. Oxford, Oxford University Press (2010).

12. Bertalanffy, L.: General System Theory. London, Penguin University Books (1968).

13. Doll, W. E.: Complexity and the Culture of Curriculum. In Mason, M.: Complexity Theory and the Philosophy of Education. New Jersey, Wiley-Blackwell (2008).

14. Woodward, J.: Industrial Organization: Theory and Practice. Oxford, Oxford University Press (1966).

15. Burns, T., Stalker, G., M.: The Management of Innovation. The Economic Journal (79)14, 403-405 (1961).

16. Burns, T.: Industry in a New Age. Gabriola Island: New Society (1963).

17. Dixon, N.: The organisational Learning Cycle. How We Can Learn collectively. London: McGraw-Hill (1994).

18. Argyris, C., Schön, D.: Organizational Learninf II: Theory, Method and Practice. Boston: Addison-Wesley (1996).

19. Senge, P. M.: The Fifth Discipline: The Art and Practice of the Learning Organization. Redfern: Currency (1990). 
20. Minati, G.: Knowledge to manage the knowledge society. The learning Organization (19)4, 350-368 (2012).

21. Talbot, C.: Theories of Performance: Organizational and Service Improvement in the Public Domain. Oxford, Oxford University Press (2010).

22. Bennet, A., Bennet, A.: Designing the Knowledge Organization of the Future: The Intelligent Complex Adaptive System. In: Hoslsapple, C.: Handbook on Knowledge management 2: Knowledge Directions. New York: Springer Science\&Business Media (2003).

23. Rozanova, N. M.: Evolution of a firm in a Digital Economy. Mirovaya Ekonomika i Medhdunarodnye Otnosheniya (63)8, 21-28 (2019).

24. Dettmers, J. et al.: Self-endangering Work Behavior. In.: Wiencke, M., Cacace, M., Fischer, S.: Healthy at Work: Interdisciplinary Perspectives. New York: Springer (2016).

25. Eurofound. 2009. Telework in the European Union - Executive Summary. http:// www.eurofound.europa.eu/pubdocs/2009/961/en/1/EF09961EN.pdf, accessed 2020/06/01.

26. Atkinson, J.: Manpower Strategies for Flexible Organisations. Personnel Management, London: Personnel Publications (16)8 (1984).

27. Pollert, A.: The Flexible Firm: A model in Search of a Reality (Or a Policy in Search of Practice?). 2015. https://www.pwc.com/us/en/technology/publications/assets/pwcconsumer-intelligence-series-the-sharing-economy.pdf, last accessed 2020/06/01.

28. Zeytinoglu, I. U.: Flexibility in Workplaces: Effects on Workers, Work Environment and the Unions. Geneva: IIRA/ILO (2005).

29. Leonard, E., Vandevelde, B.: The Coexistence of Flexibility of Labour and Commitment Strategies in Companies in Europe: Contradiction or Interaction? Journal of Human Resource Management (1)1. (1998).

30. Bredgaard, T., Larsen, F., Madsen, P. K.: The Flexible Danish Labour Market - a Review. Aalborg: Carma, Aalborg University (2005).

31. Weideman, M., Hofmeyr, K. B.: The influence of flexible work arrangements on employee engagement: An exploratory study. Journal of Human Resource Management (18), (2020).

32. Ab, W. M., Tatoglu, E.: Chasing productivity demands, worker well-being, and firm performance: The moderating effects of HR support and flexible work arrangements. Personnel Review, ahead-of-print (2020).

33. Eurofound and the International Labour Office: Working anytime, anywhere: The effects on the world of work. Publications Office of the European Union, Luxembourg, and the International Labour Office, Geneva. (2017).

34. Wojcak, E. Flexibilné formy organizácie práce. Bratislava: Ofprint, s.r.o. (2013).

35. Peltron, J. N.: E-Sphere: The Rise of the World-wide Mind. Westport: Greenwood Publishing Group (2000).

36. Johnson, L. C.: The Co-Workplace: Teleworking in the Neighborhood. Vancouver: UBC Press (2003).

37. Weideman, M., Hofmeyr, K. B.: The influence of flexible work arrangements on employee engagement: An exploratory study. SA Journal of Human Resource Management/SA Tydskrif vir Menslikehulpbronbestuur, 18(0), (2020).

38. Globálny prieskum 2016.

Industry $\quad 4.0$. https://www.pwc.com/sk/sk/publikacie/assets/2016/ceo-prieskum/industry-4-0-budovaniedigitalneho-podniku.pdf, last accessed 2020/06/01.

39. Working from Home: Estimating the worldwide potential. 2020. https://www.ilo.org/wcmsp5/groups/public/---ed_protect/---protrav/--travail/documents/briefingnote/wcms_743447.pdf, last accessed 2020/06/01 